\title{
Jonaki - An mLearning Tool to Reduce Illiteracy in Bangladesh
}

\author{
Rayhan Uddin Ahmed \\ University of Information Technology \\ and Sciences, Dhaka, Bangladesh
}

\author{
A.S.M Mahmudul Hasan \\ Bangladesh Open University, \\ Gazipur, Bangladesh
}

\author{
Mst. Afroza Sultana \\ University of Information Technology \\ and Sciences, Dhaka, Bangladesh
}

\author{
Md. Ishtiaq lqbal \\ University of Information Technology and Sciences, \\ Dhaka, Bangladesh
}

\author{
Ummay Fatama Tuj Johora \\ University of Information Technology and Sciences, \\ Dhaka, Bangladesh
}

\begin{abstract}
Bangladesh is a densely populated country with a high rate of illiteracy. The largest group that contributes to this high rate is from the adult population. Due to the widespread acceptance of mobile phones, developing mobile phone based adult literacy learning tools may help the country with literacy issues. This paper introduces one such mobile application called "Jonaki" - a simple yet powerful self-learning mobile application to teach people how to read and write Bengali. With the help of audio and video, the application creates a friendly learning environment for the illiterates. With the help of surveys on mobile phone usage by people with zero level education, the user interface of the application is made an easy one. If utilized by the government and the mobile operators, Jonaki may drastically reduce illiteracy in Bangladesh within a short span of time.
\end{abstract}

\section{Keywords}

Index Terms-mLearning, Illiteracy, Adult Literacy, Mobile Application

\section{INTRODUCTION}

By definition, literacy is the possession of skills in reading, writing and numeracy related to familiar contents and contexts and the ability to use these skills in everyday life in order to function effectively in society [1]. Literacy empowers individuals, and as a consequence, societies with propelling force toward prosperity. Therefore, it is a powerful tool for development [2]. Illiteracy, the antithesis of literacy, hampers a country's socioeconomic development as well as the welfare of the individuals burdened with it. It effects the quality of life for people due to the obstacles it erects to using someone's full potentials.

In Bangladesh the rate of literacy is very low (Fig. 1), which has a direct impact on the country's welfare and development. The largest group that contributes to the illiteracy rate of Bangladesh is from the adult population [3, 4]. Equipping this group with literacy will contribute greatly to the country's development.

But liberating these people from illiteracy is not an easy task to undertake. Illiterate adults have shown aversion to curricular activities to learn reading and writing skills for a number of reasons - earlier discouragement faced due to their inability to learn and/or a sense of failure that produced broken confidence[5] are to name a few. It may, therefore, be a very difficult task to reach out to them and inspire them to undertake learning again. Some have suggested the use of elearning as a potential medium of lesson delivery for such a group [5]. A significant study in Egypt showed that lessons delivered through cell phones (mLearning) may have great potential as well[6].

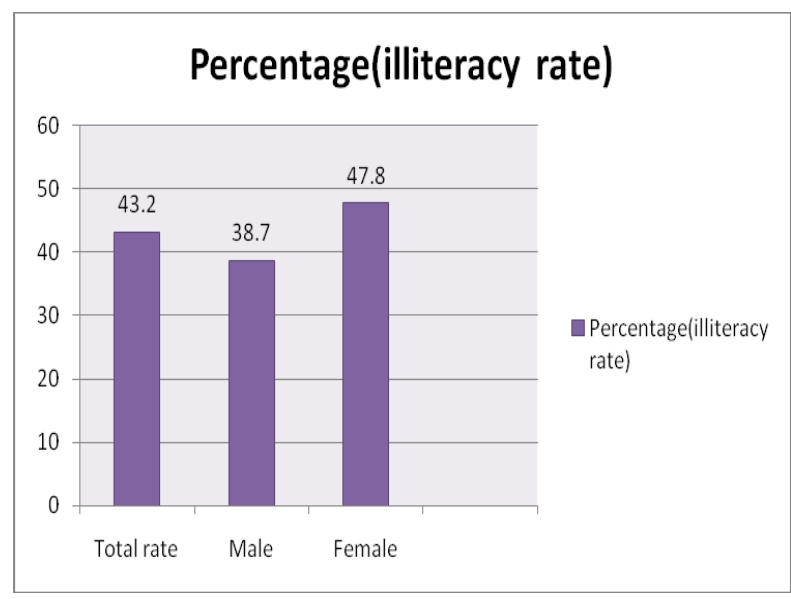

Fig 1: Bar chart of illiteracy rate [5]

\section{OBJECTIVE OF THE STUDY}

To reach the adult group of people to teach them reading/writing/numerical knowledge, mLearning can be an effective way since it spurs curiosity and at the same time removes the shame that may be associated with being in a class room setting. A self-controlled/self-paced mobile lesson delivery application has the potential to remove the embarrassment that an adult may feel if lessons were delivered in a class room in front of others.

Mobile phone makes life easier than the old times in different way. Communication through this device decreased lots of administrative and transportation costs increasing efficiency in business world. The wide usage of mobile phones revolutionized the communication in day-to-day life. They allow us to communicate with friends and other not being confined to a place with a landline. For example, in emergency situation in rural area people do not need to find a landline phone to call someone to help anymore. Instead, they use mobile phone which has immediate access to needed organization to solve the problem [7]. Furthermore, in Bangladesh, mobile platform is one of the most powerful delivery medium for lessons due to its wide-spread acceptance in all areas/ages.

In this paper, a mobile application called "Jonaki" is introduced which is developed to deliver lessons on reading/writing Bengali alphabets. The meaning of the word 
Jonaki is firefly - something that gives hope to people in utter darkness. The application is geared toward the adults with literacy issues. The application was developed with usability in mind since it is to be used by a section of the population that are not literate. It is an application that allows users to set their own pace in learning activities as well.

The rest of the paper is organized as follows - Section 2.0 introduces works related to the project. Section 3.0 sets the background of the project and includes the survey that determined the feasibility of a mobile app for the illiterates. Section 4.0 introduces Jonaki and its user interfaces. Section 5.0 discusses Jonaki's strengths and weaknesses as well the future plan for it. Finally, the Conclusion section ends the paper with a summary.

\section{RELATED WORKS}

In a project in Egyptian rural areas, researchers used mobile phones to deliver lessons to people with literacy issues [8]. They were able to prove that in most cases using mobile phone actually helped individuals achieve better progress than they could achieve using traditional delivery methods. This study is significant for us since it establishes the validity of using mobile phone as medium for conveying lessons. But this study did not use any novel application to literate people like Jonaki.

There are several related mobile application that are also available [1]. In Afghanistan, Paiwastoon's Ustad Mobile [13] ("mobile teacher") application puts mobile learning software on any phone with a memory card. Relying only on technology already widely used by Afghans of all ages and education levels, Ustad Mobil is a sustainable and scalable option for education and training initiatives of all sizes.

Ustad Mobil can be used to turn virtually any curriculum, for any subject, into an easily installed, multimedia application. Its metrics functionality offers teachers, trainers, and managers a powerful tool for monitoring the learning process, even at a great distance. This innovative application even enables reporting of a user's learning time and quiz scores over Bluetooth to her or his trainer or teacher's phone. With a basic data connection, a trainer's phone can easily transmit statistics from remote project sites to a secure online database, enabling real-time monitoring of education and training projects from anywhere in the world.But its scope is wider than the scope of Jonaki. It was developed to be a teacher's aide in a classroom for any type of student population. Helping in teaching literacy is only a part of it, whereas, it is the sole purpose of Jonaki.

In Pakistan illiteracy problem is also a burden to their development process. To eradicate this kind of problem UNESCO took initiative and Nokia Pakistan developed the Application "e-Taleem" [14] which is used to educate the illiterate people. They learn to write the alphabet and to read with emphasis on phonics with the help of this mobile application at primary stage. After completing this stage they learn can learn also about different topics like health and hygiene, language, religious values, numeracy. This mobile application is also a great example why this kind of mobile application is needed in Bangladesh which is a effective way to remove the curse of illiteracy.

Now days there are also different mobile applications for learning. Being Global, Word Lens, FREE [Language] Tutor Games, iTranslate and many more are for learning language. One can know about history or geography using different mobile application like Today in History, Virtual Water, Google Earth, Kids World Maps and many others [15].

Jonaki is unique on several accounts - it is the first such application for the Bengali language. It is also geared toward being a self-learning application where individuals will need little to no help to use and learn - they can learn at a pace that is comfortable for them. Jonaki is also much focused - it is developed with a single goal in mind, that is to literate people.

\section{DETERMINING VALIDITY, FEASIBILITY, AND USER INTERFACE OF JONAKI}

The development of Jonaki was undertaken to reduce illiteracy in Bangladesh. The validity of this cause to be determined by analyzing the current literacy situation in Bangladesh, to understand if there is really a need for such an application or not.

Another validity check had to be done to address the feasibility of developing a mobile application for a population that cannot even read or write. This validity check had two facets - one determined if illiterate people use cell phones or not, and another determined the types of application they use to understand their skill level with cell phones. It was expected that Jonaki would be a self- study tool where individuals could use it on their own. So an easy to use interface was at the core of "Jonaki" development strategy.

Online research and surveys were carried out to answer the fundamental questions mentioned above.

Online researches were carried out to understand the current situation with literacy in Bangladesh. A simple search in google.com with simple phrase such as "Literacy in Bangladesh" yielded wealth of information. Data were collected form articles, websites of multiple government and private organizations. The data clearly showed the need for effective methods to reduce illiteracy.

In order to validate the use of mobile phones for the application, data were collected from individuals with zero level education. Appropriate questionnaire were prepared to collect these valuable data. Here are the questions used in the survey are listed below -

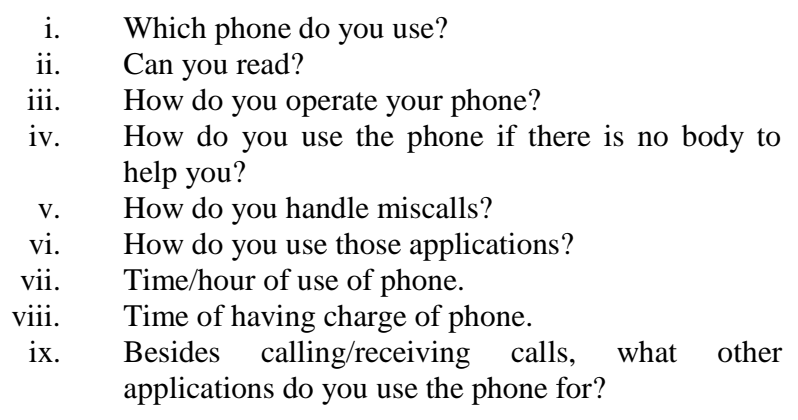

For people living in the capital city Dhaka, face to face interviews were carried out in areas such as Khilbarirtech, Kamrangirchor, Beribadh, Boubazar, Hazaribag, Gulistan, Comlapur Railway and Farmgate using questionnaire prepared. Phone interviews were carried out for rural areas such as Natore(Bonpara), Chittagong(potiya), Jassore, Bogra(Garidaha), Rajshahi(Bagha) and different other villages. Total number of respondents was 80 . 


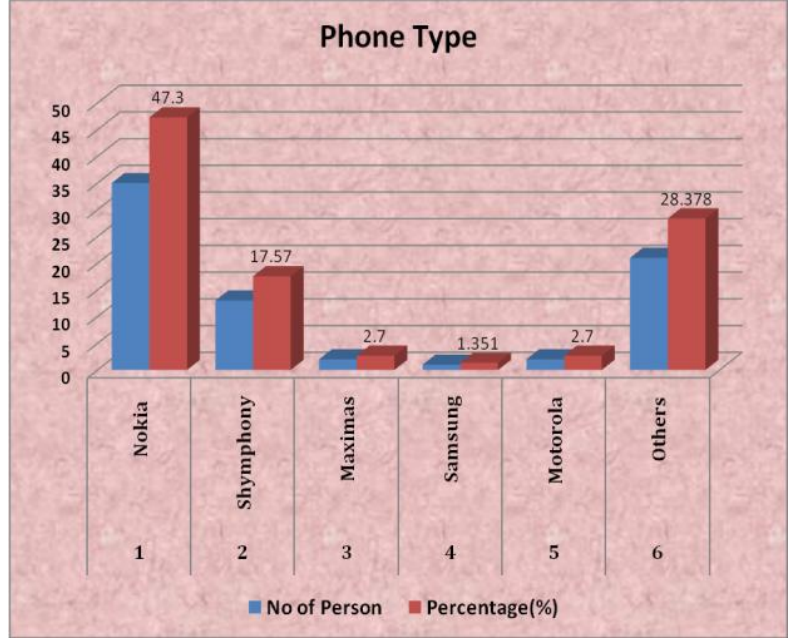

Fig 2: Phone types used by people with zero level education

Tables and charts were created to analyze the data (fig. 2). Collected data showed Nokia and Symphony to be the most widely used phones by the target population (Fig 2). Both these types support J2ME platform.

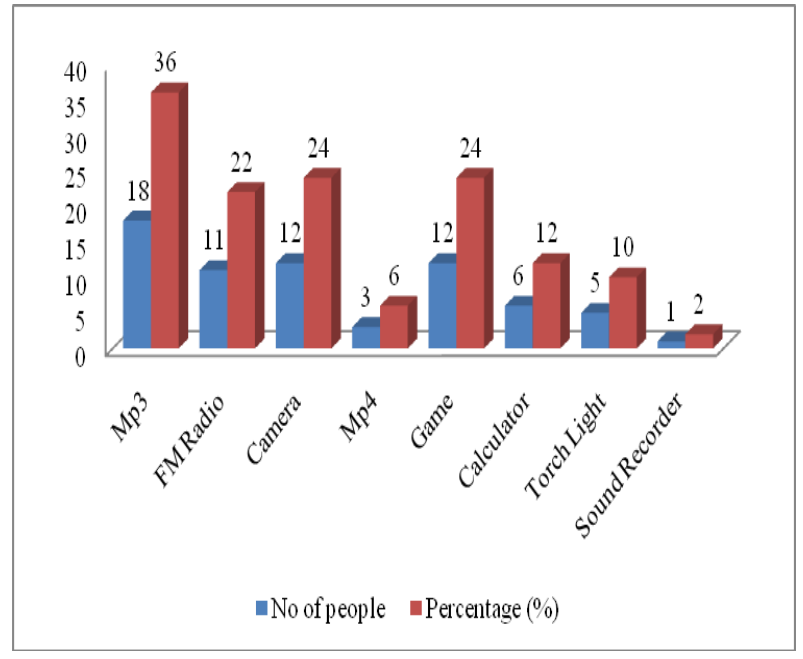

Fig 3: Bar chart of Uses Mobile Applications of Zero Level Education people

From the data, several frequently used mobile applications were identified - Mp3, FM Radio, Camera, Mp4, Game, Calculator, Torch Light, and Sound Recorder. The percentage rate of using Mp3, FM Radio, Camera, Mp4, Game, Calculator, Torch Light, and Sound Recorder applications are $36 \%, 22 \%, 24 \%, 6 \%, 24 \%, 12 \%, 10 \%$, and $2 \%$ respectively (Fig. 3). This data also indicated the mobile application usage skills of adults with zero level education. This data was the principle guiding force for the user interface of Jonaki. This data also drove the decision to use J2ME as the technology platform for the application.

One clarification of the data is needed here. A small percentage of people were shown using the calculator. A natural question that might arise is how an illiterate person can use a calculator. The answer lies in the following fact - a few of the respondents learned number recognition to do calculations they frequently needed. Data collected evidently showed that J2ME would be best platform to choose for Jonaki. Most phones used by the people interviewed used phones with J2ME enabled. So a J2ME application will have the maximum reach.

Important data about the user interface design for Jonaki was also revealed through the survey. Most of the people surveyed used simple application that used simple selection lists and required few key presses. This helped in the design process for the application. Jonaki's interface was designed to closely resemble those simple application that these people use.

\section{DEVELOPING JONAKI}

NetBeans IDE 7.0 with JDK1.7 were used to develop Jonaki. The simulator available in the IDE was used to conduct the initial testing. Jonaki was later deployed on several mobile phones for further testing.

At first, the video of bengali letters is captured which are display on screen of mobile. The videos of 11 Bangla letters are captured separately.

Capturing Video with Audio: For capturing video Digital Camera are taken and for writing letters some offset papers and gel pen are used. Then one by one letter with audio sound is written by speaking and capturing videos. For getting a perfect video of each 11 letters many shots have taken but before capturing video available day light is also needed. After capturing all the videos, the best 11 is collected.

Compressing Video: The size of captured videos is too large for the mobile application. As the size of phone memory is relatively small, the video files are needed to be compressed. Because of this, video compression software is used.

Video Compression software tools: Mobile application has some limitations about memory means that it's a limited lowend device with a small amount of memory. If the actual video size is used in this mobile application then the small device with low memory will not be able to play those videos. So video compressing software "Format Factory version 1.65" is used to compress those videos. After compressing those videos, comparatively small sized videos are found which are necessary for this mobile application.

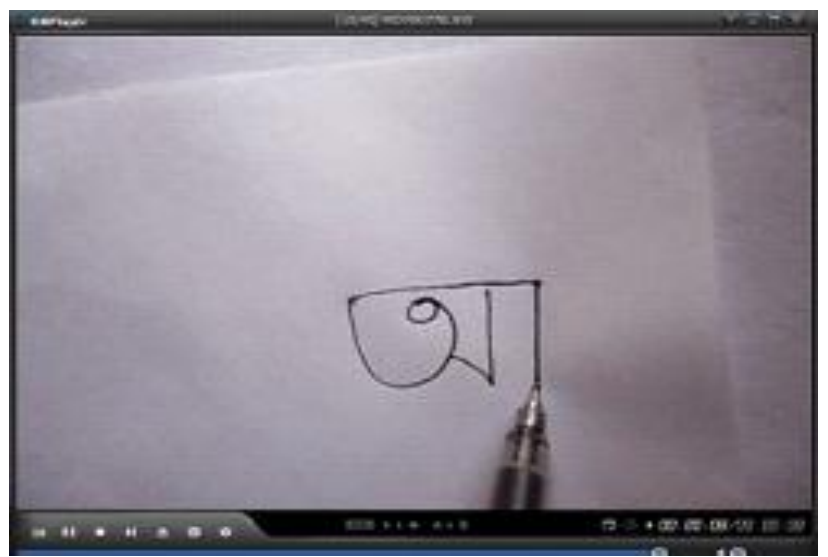

Fig 4: The screen shot of 2nd Bengali letter

Videos were created for each letter in the alphabet (Fig. 4). As one person wrote and pronounced each letter, another person video-taped it. Each letter had its own video to keep the size small to avoid any issue with the default video player in J2ME. Each video was compressed using Format Factory. Panasonic Lumix DMC-FP2 Digital Camera was used for taking all the videos. The aim of using mobile-based user interface is obviously seen as- 
- Task support and efficiency: One of the reasons is the UI should well matches with users' tasks and needs. UI should be simple and user can reach what s/he wants via reasonable number of clicks.

- Understandability: Users can understand the basic UI of the application easily and in this term, the UI is simple and understandable. Users can use all functions of the application without any documentation or user guides and they can reuse their knowledge about the application when they need.

- Safety: Users should have forgiveness if they had done unexpected action as delete a task or adding expired task.

- Consistency and familiarity: The UI of application should be consistent with another UI formats and users can be apply their knowledge, experience of the similar UIs or UI standards while using Jonaki(mobile application).

\section{USING JONAKI}

Jonaki is shown on mobile phone's application menu with the pictorial representation of the first vowel (अ) of the Bengali alphabet (Fig. 5).

Once the user selects the application to run, a list of all the letters with their corresponding pictorial representation is shown (Fig. 5).

A user can select any of the letters using up-down keys (Fig. 5) at their own will. Once selected, pressing the middle button starts the video of the selected letter. As the letter is being drawn in the video, the pronunciation can also be heard by the user.

The videos were created to serve several purposes - to show how to hold a pen and to show how each letter is actually written. This part is important to teach people writing Bengali. The videos clearly shows the paths to follow to write each letter.

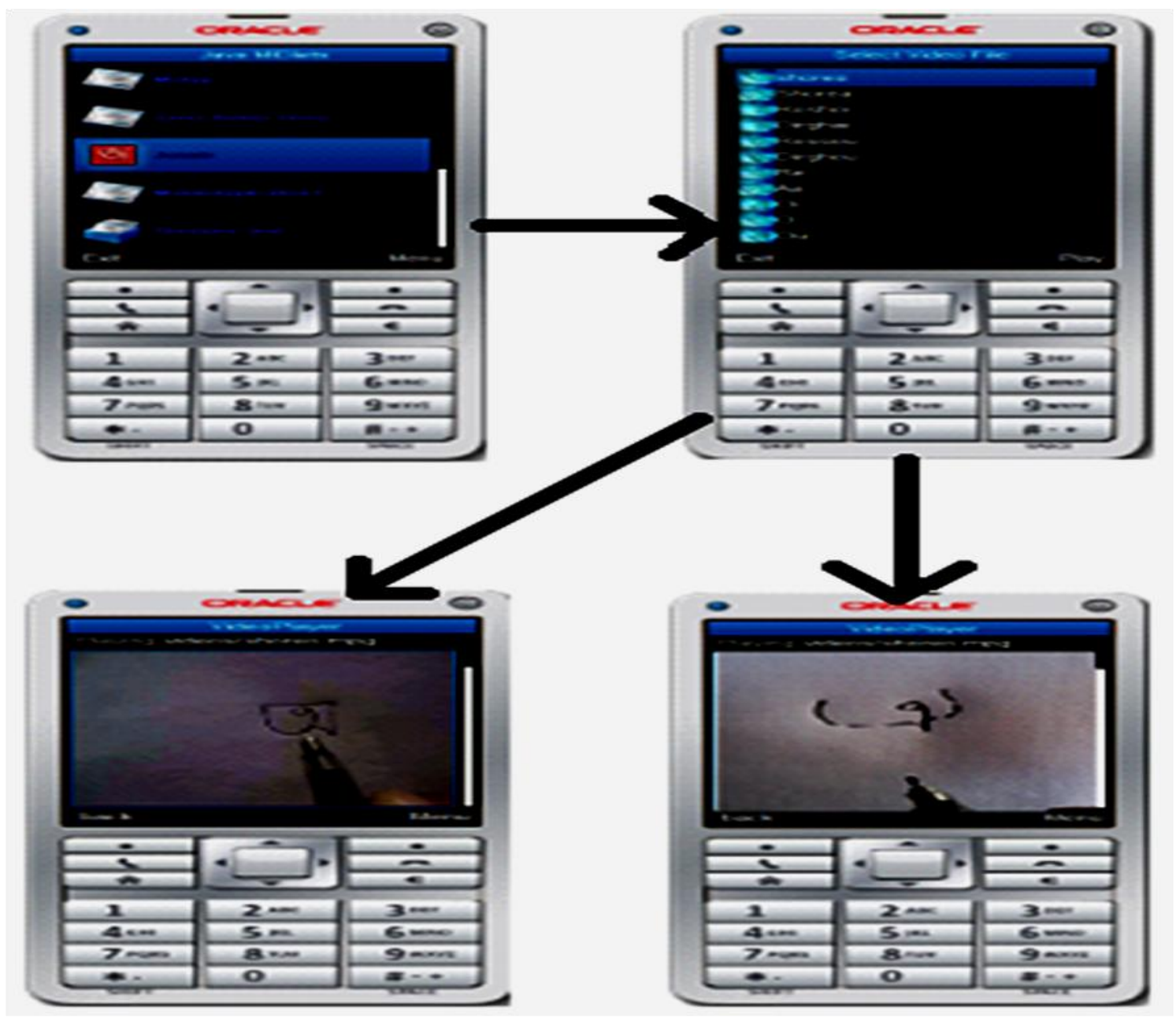

Fig 5: Jonaki flow of operation

\section{STRENGTHS, WEAKNESSES AND FUTURE PLAN}

Jonaki was developed based on data collected from interviews. The interface is kept simple to make it usable by illiterate people without any help from others. Jonaki was deployed on a limited number of devices to test its operations. Unfortunately, it could not be field tested due to resource constraints. It needed to be deployed on cell phones of a given number of illiterate people for testing. This testing was necessary to get an understanding of its actual effectiveness. Hope to do that in the future with the help of the government and the mobile phone operators.

As of now, Jonaki has some limitations - it can only show the Shorobornos (vowels). The videos for Benjonbornos (consonants) and word making will be added at a later time. 
Another limitation of the application is that it can only work on J2ME enabled devices. It is planned on porting it to other devices in the future.

\section{CONCLUSION}

To facilitate the efforts to reduce illiteracy in Bangladesh, "Jonaki" - an easy to use J2ME mobile application is developed. The application uses video and audio to show people how to draw different letters in the alphabet sets. In order to choose the technology to use for maximum reach of the target population, surveys were conducted to find out what types of mobile phones are in use by people with zero level education. Our data also helped us understand the type of interface that would be needed by showing us the way these people use their phones and the applications they frequently use. Our objective of developing the application and testing its deployment were fulfilled. Jonaki has the potential to help eliminate illiteracy in Bangladesh.

Currently there are some limitations of this application. Initiative will be taken to make this application more useful and user friendly. The following features will be included in future:

- "Benjon Borno" following "Shorborno" in "Jonaki" mobile application.

- $\quad$ word making feature associated with related letters with image.

- English alphabet in Jonkai mobile application.

- Predefined button for next/previous action in "Jonaki" mobile application.

- Deploy the "Jonaki" application at next.

\section{REFERENCES}

[1] M. Ahmed, S. R. Nath, K. S. Ahmed, "Literacy In Bangladesh - NEED FOR A NEW VISION," Education Watch, 2002

[2] S. Hasaba, "Education for All: Reflecting on Adult Literacy Learning for Socio-Economic Development in Uganda," Academic Research International, Vol. 2, Issue 2, March, 2012

[3] "Report on the Bangladesh Literacy Survey," Industry and Labour Wing, Bangladesh Bureau of Statistics, Statistics Division, Ministry of Planning, June, 2011

[4] S. R. Nath, "Self-report and Test Discrepancy: Evidence from National Literacy, Survey in Bangladesh," BRAC Research Report, November, 2005

[5] "Bar chart of illiteracy rate". [Online]. Available: http://en.wikipedia.org/wiki/List_of_countries_by_literac y_rate. [Accessed: July 08, 2014]

[6] J. Fletcher, K. Nicholas, N. Davis, "Supporting Adults to Address Their Literacy Needs Using E-learning," Journal of Open, Flexible, and Distance Learning, Vol. 15, Issue 1, Pages 17-27, 2010

[7] Gunay Gozalova, "Mobile phones have made life easier", Available: http://www.academia.edu/5168391/Mobile_phone s_have_made_life_easier.
[8] M. Kam, "Language and literacy learning in developing communities via cellphones," ICLS '10 Proceedings of the 9th International Conference of the Learning Sciences, Vol. 2, Pages 106-108, 2010

[9] H. Knoche, J. Huang, "Text is not the enemy: How illiterates' use their mobile phones," NUIs Workshop, Chicago, May, 2012

[10] Y. Fanta-Vagenshtein, "How Illiterate People Learn: Case Study of Ethiopian Adults in Israel," Journal of Literacy and Technology, Vol. 9, Issue 3, December, 2008

[11] Z. Gong, J. D. Wallace, "A Comparative Analysis of iPad and Other M-learning Technologies: Exploring Students' View of Adoption, Potentials, and Challenges," Journal of Literacy and Technology, Vol. 13, Issue 1, February, 2012

[12] K. C. Barker, "Linking Adult Literacy and eLearning," ABC CANADA Literacy Foundation, 2005

[13] "Ustad Mobile - Mobilizing Education for All,". 2014 [Online]. Available: https://www.ustadmobile.com. [Accessed: July 08, 2014]

[14] "eTaleem - United Nations Educational, Scientific and Cultural Organization,”. 2014. [Online]. Available: http://www.unesco.org.pk/education/etaleem.html. [Accessed: July 08, 2014]

[15] Anthony Jackson, “Apps for Global Mobile Learning". [Online]. Available: blogs.edweek.org/edweek/global_ learning/2012/06/apps_for_global_mobile_learning_part 2.html

\section{AUTHOR PROFILE}

Raihan Ahmed has a B.Sc. and an M.Sc. in Computer Science from the State University of West Georgia. He has been working as a Software Engineer for over a decade since his graduation. $\mathrm{He}$ is currently teaching in the Computer Science and Engineering department, University of Information Technology \& Sciences, Dhaka. His research interests include, but are not limited to, Software Engineering, Machine Learning and Human Computer Interaction.

A. S. M Mahmudul Hasan has a B. Sc and M. Sc in Computer Science and Engineering from Jahangirnagar University, Bangladesh. $\mathrm{He}$ is working as a Lecturer in Computer Science and Engineering at Bangladesh Open University. His research interest includes Natural Language Processing, Image processing and Human Computer Interaction.

Mst. Afroza Sultana has completed B. Sc (Hons) in Comuter Science and Engineering from the University of Information Technology and Sciences, Dhaka, Bangladesh.

Md. Ishtiaq Iqbal has completed B. Sc (Hons) in Comuter Science and Engineering from the University of Information Technology and Sciences, Dhaka, Bangladesh.

Ummay Fatama Tuj Johora has completed B. Sc (Hons) in Comuter Science and Engineering from the University of Information Technology and Sciences, Dhaka, Bangladesh. 